\title{
Bioavailable Chemical Forms of Copper, Iron, and Zinc in Livestock Compost
}

\author{
Toyotaka IsODA and Ryota SHINOHARA \\ Graduate School of Environmental and Symbiotic Sciences, Prefectural University of Kumamoto, \\ 3-1-100 Tsukide, Kumamoto 862-8502, Japan
}

(Received December 24, 2012; Accepted January 25, 2013)

\begin{abstract}
A cultivation experiment was conducted to investigate the change of chemical forms of $\mathrm{Cu}, \mathrm{Fe}$, and $\mathrm{Zn}$ in compost produced from horse dung (HDC) and that produced from swine manure (SMC). A mixture of silica gel and sieved HDC and that of silica gel and sieved SMC were used as media to cultivate peas (Pisum sativam L.) in order to determine bioavailable chemical forms of $\mathrm{Cu}, \mathrm{Fe}$, and $\mathrm{Zn}$. $\mathrm{Cu}$ and $\mathrm{Fe}$ were primarily found in an organic complex fraction and residue fraction of HDC and SMC. Zn was primarily found in an iron and manganese oxide fraction and an organic-complex fraction. There was little change in the concentration of "bioavailable fractions," such as water-soluble, exchangeable, and carbonate. However, the amount of $\mathrm{Cu}$ and $\mathrm{Fe}$ in the organic complex fraction decreased significantly and that $\mathrm{Zn}$ in the iron and manganese oxide and organic complex fractions also decreased significantly. These results indicated that the transportation of $\mathrm{Cu}, \mathrm{Fe}$, and $\mathrm{Zn}$ to plants affected their chemical forms. The associated fraction played a role in the storage (sink) of $\mathrm{Cu}$, $\mathrm{Fe}$, and $\mathrm{Zn}$ when the amount decreased significantly.
\end{abstract}

Keywords : chemical form of heavy metals, cultivation experiment, livestock compost, sequential extraction, sink

\section{INTRODUCTION}

The Act on the Appropriate Treatment and Promotion of Utilization of Livestock Manure was implemented by the Japanese government in 1999 (Ministry of Agriculture, Forestry and Fisheries, Japan, 1999) to regulate storage and treatment of effluvia and control pollution of river water and ground water caused by livestock waste. The government of Japan has also endorsed effective reuse of livestock waste as an organic resource aiming at a gradual transition to a sound material-cycle society (Ikefuchi, 2007). Consequently, a large amount of livestock waste has been recycled as compost. However, high concentrations of heavy metals, particularly $\mathrm{Cu}$ and $\mathrm{Zn}$, in livestock feed are problematic. $\mathrm{Cu}$ and $\mathrm{Zn}$ are added to promote somatic growth of piglets (European Commission, 2003; Mizukami et al., 2006). It has been reported that feeding high dietary $\mathrm{Cu}$ to piglets increases their birth number and weight (Gromwell et al., 1993). In addition, to prevent anemia or increase in hemoglobin of pigs, use of Fe injections for pigs is a common practice (Jolliff and Mahan, 2011). The reasonable concentration of $\mathrm{Cu}$ in feeds for neonatal piglets is recognized to be $5 \mathrm{mg} \mathrm{kg}^{-1}$; however, regulations permit $125 \mathrm{mg} \mathrm{kg}^{-1}$ (Japan Livestock Industry Association, 2005). Pig feed in Japan tends to contain excess amounts of $\mathrm{Cu}$. Consequently, $\mathrm{Cu}$ and other heavy metals gradually accumulate in compost. Hseu (2004) reported that the concentration of $\mathrm{Cu}$ and $\mathrm{Zn}$ in compost produced from swine manure was the highest among nine different types of composts. It has been estimated that the long term application of compost containing high concentrations of heavy metals will hinder the growth of plants and/or cause soil contamination (Novak et al., 2004).

It is well known that the bioavailability of heavy metals for plants depends on the chemical form of a metal. Zhao et al. (2011) investigated the geographical distribution for every chemical form of heavy metals in the soil and concentration of heavy metals in rice produced in the study region. They reported that iron and manganese oxide, exchangeable, and organic complex fractions can be considered as bioavailable fractions. However, this method is not what measured the concentration change of heavy metals for every chemical form in soil by absorption of plants. From this reason, it is surmised that the method of them is an indirect technique. To clarify the bioavailability of various chemical forms of heavy metals, it is necessary to analyze the amount of heavy metal transported from a medium and/or soil to plants. In this study, a cultivation experiment using compost was conducted to determine the relationship between chemical forms of $\mathrm{Cu}, \mathrm{Fe}$ and $\mathrm{Zn}$ and bioavailability for plants. $\mathrm{Cu}, \mathrm{Fe}$ and $\mathrm{Zn}$ in each chemical fraction of compost were analyzed after the cultivation experiment, and the distribution and transference of metals was investigated.

\section{MATERIALS AND METHODS}

\section{Chemicals}

The reagents used in this experiment were analytical grade $\mathrm{HNO}_{3} 60 \%, \mathrm{HCl} 35 \%, \mathrm{CH}_{3} \mathrm{COONH}_{4} 99 \%, \mathrm{H}_{2} \mathrm{O}_{2}$

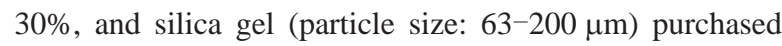
from Wako Pure Chemical Industries, Ltd. (Osaka, Japan). Analytical grade $\mathrm{HClO}_{4} 60 \%$, $\mathrm{HF} 50 \%$, and $\mathrm{CH}_{3} \mathrm{COOH}$

Corresponding author: Ryota Shinohara, fax: +81-96-321-6711, e-mail : shinoryo@pu-kumamoto.ac.jp 
99\% were purchased from Kanto Chemical Co., Inc. (Tokyo, Japan) .

Selection of a dilution medium for compost

The concentration of inorganic and organic matter in animal compost was too high to cultivate plants. Therefore, a dilution medium was required. Silica gel was selected as the dilution medium because it has a variable surface charge and contains little $\mathrm{Cu}, \mathrm{Fe}$, and $\mathrm{Zn}$ and little organic matter. Kuroboku (andosol), which is produced from volcanic ash, is a significant component of approximately half of the arable soil in Japan and it contains humus abundantly (Ministry of Agriculture, Forestry and Fisheries, Japan, 2007). Additionally, Bohn (2001) reported that allophen was first noted in Japanese soils derive from volcanic ashes. Since allophone, humus (Mcbride, 1994), and silica gel (Bartoli and Philippy, 1987; Saeki, 2006) have a variable surface charge, it was thought that silica gel was suitable to model Japanese agricultural soil.

Concentrations of $\mathrm{Cu}, \mathrm{Fe}$, and $\mathrm{Zn}$ in HDC and SMC

Concentrations of $\mathrm{Cu}, \mathrm{Fe}$, and $\mathrm{Zn}$ in horse dung compost (HDC) and swine manure compost (SMC) were determined by atomic absorption spectrometry after digestion of the composts. One gram of each compost sample was placed in a $100 \mathrm{~mL}$ polytetrafluoroethylene (PTFE) vessel and digested with $\mathrm{HNO}_{3}, \mathrm{HClO}_{4}$, and HF. After the solution was diluted with $0.1 \mathrm{~mol} \mathrm{~L}^{-1} \mathrm{HNO}_{3}$, concentrations of $\mathrm{Cu}, \mathrm{Fe}$, and $\mathrm{Zn}$ were determined with a flame atomic absorption spectrometer (HITACHI Z-5310, Japan).

Chemical forms of $\mathrm{Cu}, \mathrm{Fe}$, and $\mathrm{Zn}$ in HDC and SMC

A partially modified sequential extraction method based on a previously reported method (Tessier et al., 1979; Kitano and Fujiyoshi, 1980; Nakashima, 1982) was used to define the chemical forms of $\mathrm{Cu}, \mathrm{Fe}$, and $\mathrm{Zn}$ in the composts. One gram of compost was transferred to a centrifuge bottle and processed using the process shown in Fig. 1. Fe and $\mathrm{Zn}$ in all fractions of HDC were determined with the flame atomic absorption spectrometer. Because of the low concentration of $\mathrm{Cu}, \mathrm{Cu}$ in all fractions of HDC was determined with a flameless atomic absorption spectrometer (HITACHI Z-2700, Japan). There were sufficient concentrations of $\mathrm{Cu}, \mathrm{Fe}$, and $\mathrm{Zn}$ in $\mathrm{SMC}$ to permit the use of the flame atomic absorption spectrometer.

Chemical forms of $\mathrm{Cu}, \mathrm{Fe}$, and $\mathrm{Zn}$ in silica gel

The chemical forms of $\mathrm{Cu}, \mathrm{Fe}$, and $\mathrm{Zn}$ in silica gel used as the dilution medium were investigated. Silica gel was pretreated by washing with $0.1 \mathrm{~mol} \mathrm{~L}^{-1} \mathrm{HNO}_{3} 3$ times and rinsing with pure water. The cleaned silica gel was dried at $110^{\circ} \mathrm{C}$ for $24 \mathrm{~h}$. After drying, $2 \mathrm{~g}$ of silica gel was transferred to a centrifuging bottle and sequentially extracted using the process shown in Fig. 1. Cu, Fe, and $\mathrm{Zn}$ in all fractions were determined with the flameless atomic absorption spectrometer. All quantitative analyses were repeated 4 times for each sample.

HDC/SMC-silica gel acclimatization experiment

Before the cultivation experiment, HDC and SMC (HDC/SMC) were mixed with silica gel and an acclimatization experiment was conducted, as illustrated in Fig. 2. This experiment investigated whether a change in concentration of $\mathrm{Cu}, \mathrm{Fe}$, and $\mathrm{Zn}$ for each chemical form with

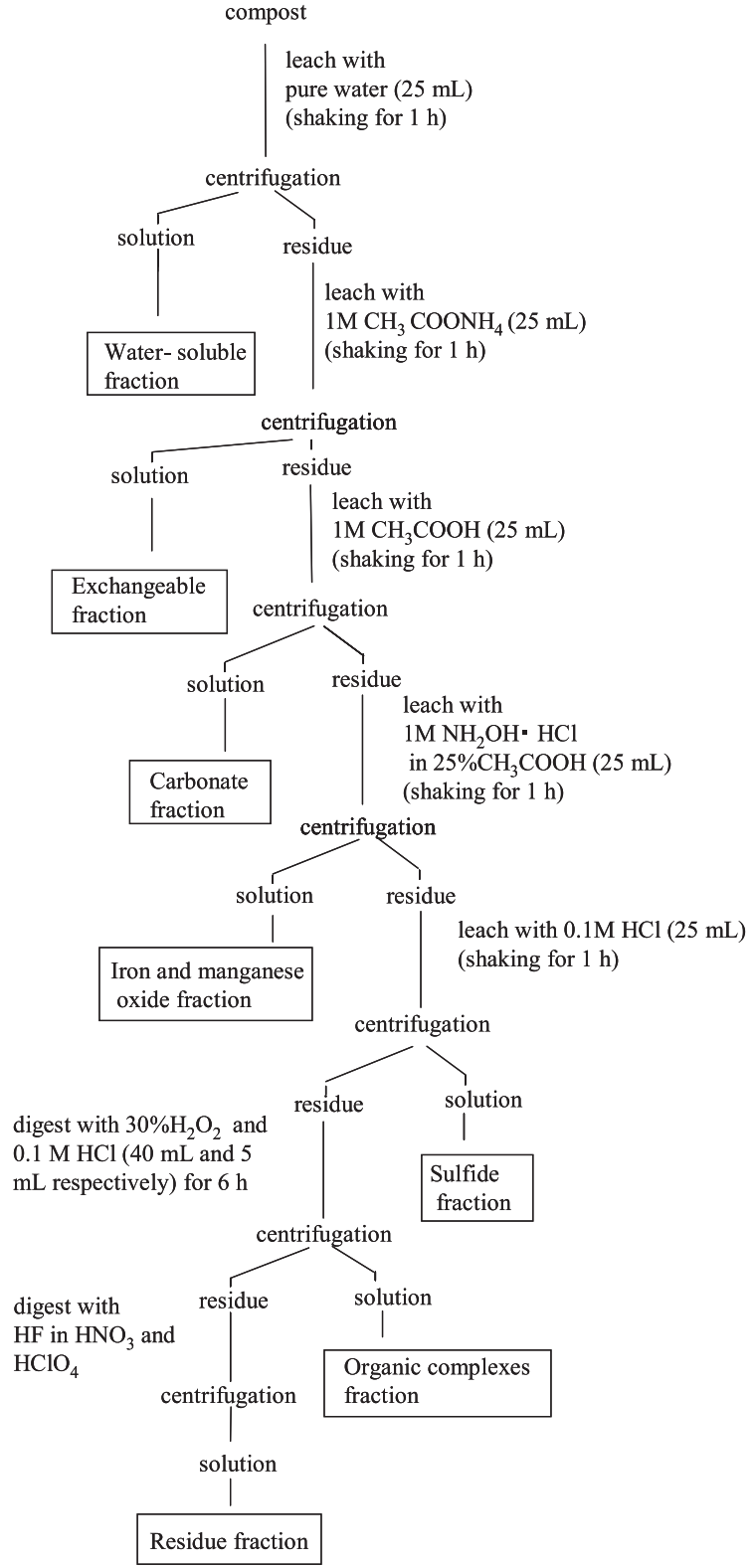

Fig. 1 Sequential extraction flow chart.

temporal would occur. HDC/SMC was put through a 2-mm sieve prior to mixing with the cleaned silica gel. The mixing ratios were taken from guidelines provided by the Ministry of Agriculture, Forestry and Fisheries (2005). According to these guidelines, the maximal permissible amount of compost that could potentially be used on farmland is $3.5 \mathrm{t}$ per $10 \mathrm{a}$. If the thickness of a plow layer and the bulk density are $22.5 \mathrm{~cm}$ and $1 \mathrm{~g} \mathrm{~mL}^{-1}$, respectively, the applicable amount of compost is $3.5 \mathrm{t}$ per $225 \mathrm{t}$ of soil. On the basis of this ratio, $0.3 \mathrm{~g}$ of SMC was used with $19.7 \mathrm{~g}$ silica gel. To equalize the concentration of $\mathrm{Cu}$ in the HDCsilica gel and SMC-silica gel mixtures (HDC/SMC-silica gel), the ratio of HDC to silica gel was determined to be 4 : 16 (total weight was $20 \mathrm{~g}$ ). A half-cut $100 \mathrm{~mL}$ polypropylene bottle was prepared as a container for the acclimatization experiment. Pure water $(15 \mathrm{~mL})$ was added to HDC/SMC-silica gel by agitation. The mixtures were then stabilized for $24 \mathrm{~h}$. After the initial stabilization, the 

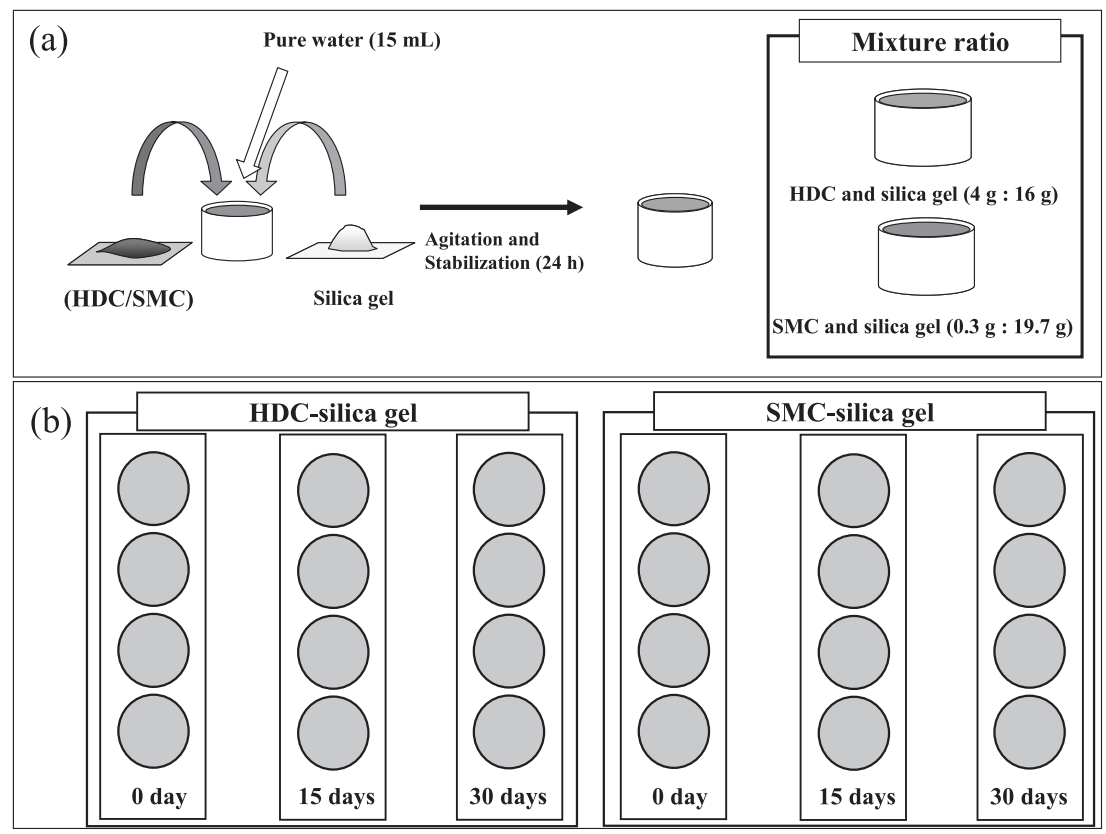

Fig. 2 Schematic diagrams of HDC/SMC-silicagel acclimatization experiments; (a) Mixing ratios of composts to silica gel. (b) Layout of acclimatization experiment. These samples (HDC/SMC-silicagel) were stabilized in growth chamber with addition of moisture. Cultivation period were 0,15 and 30 days and repeated counts were 4 for each sample.

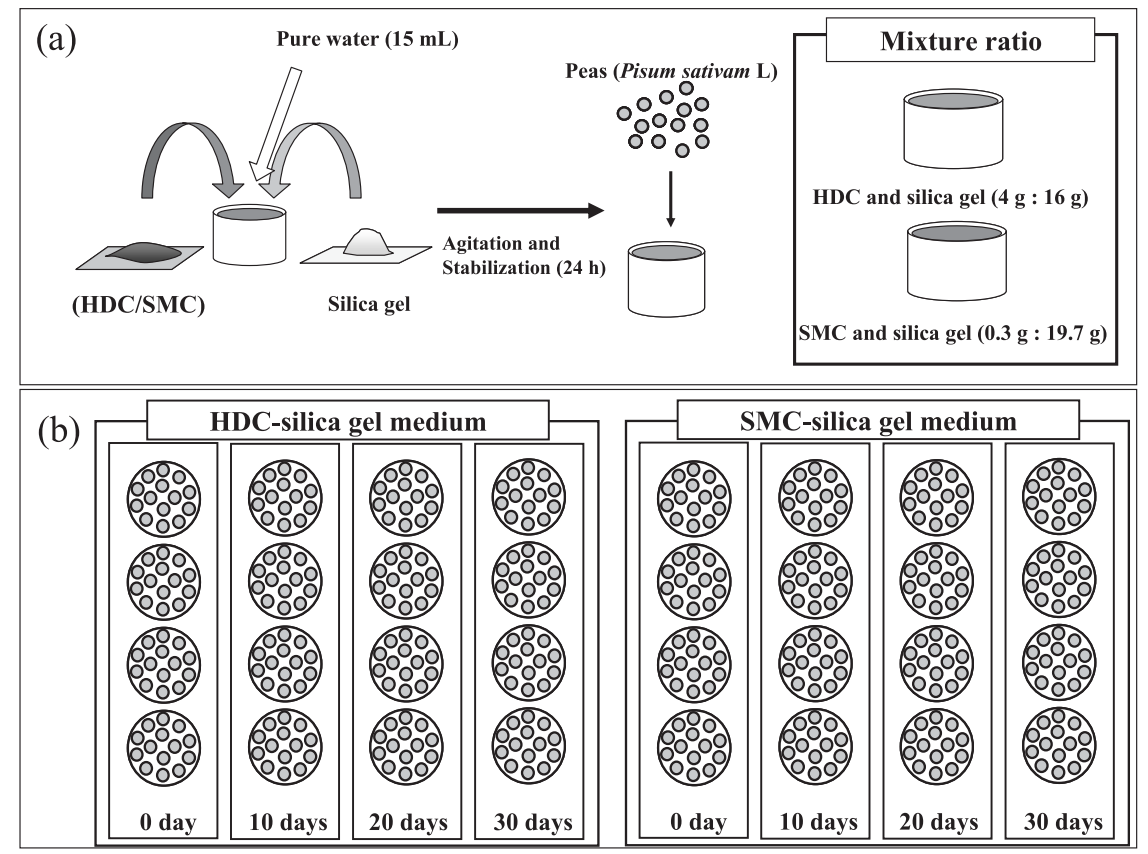

Fig. 3 Schematic diagrams of the peas cultivation experiment. (a) Mixing ratios of composts to silicagel. (b) Layout of cultivation experiment. These samples (HDC/SMC-silicagel mediums) were cultivated in growth chamber with addition of moisture. Cultivation period were $0,10,20$ and 30 days and repeated counts were 4 for each sample.

medium was stabilized again for 0,15 , and 30 days. In addition, in order to prevent dryness of HDC/SMC-silica gel, $5 \mathrm{~mL}$ of pure water was added to it once every 3 days. After the experiment, $2 \mathrm{~g}$ of each sampled HDC/SMCsilica gel was transferred to centrifuging bottles and sequentially extracted according to the process shown in Fig. 1. All analyses were repeated 4 times for each sample.

Chemical forms of $\mathrm{Cu}, \mathrm{Fe}$, and $\mathrm{Zn}$ in the HDC/SMCsilica gel medium during the cultivation experiment

The cultivation experiment was conducted using peas
(Pisum sativam L). HDC/SMC was mixed with cleaned silica gel and these mixtures were used as the media for the cultivation experiment. Figure 3 illustrates the mixing ratios of composts to silica gel. 14 sprouted peas were sown in the prepared media. The peas were grown in a growth chamber under $12 / 12 \mathrm{~h}$ fluorescent light at a stable temperature $\left(25^{\circ} \mathrm{C}\right)$.

The cultivation periods were $0,10,20$, and 30 days. After each cultivation period, the media were sampled and analyzed according to the process shown in Fig. 1. 

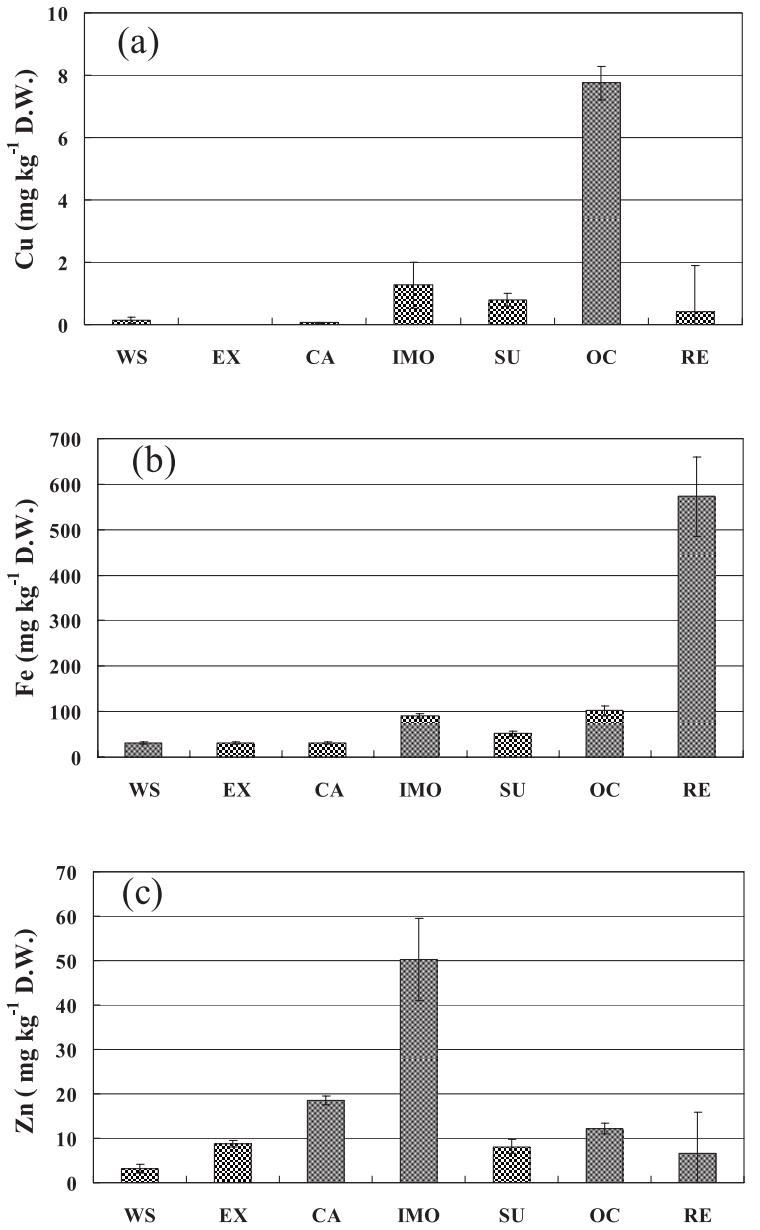

Fig. 4 Chemical forms of $\mathrm{Cu}$ (a), $\mathrm{Fe}(\mathrm{b})$, and $\mathrm{Zn}$ (c) in horse dung compost (HDC). WS: water soluble, EX: exchangeable, CA: carbonate, IMO: iron and manganese oxide, SU: sulfide, OC: organic complex, and RE: residual. Vertical bars indicate standard errors.

\section{RESULTS}

Concentrations and chemical forms of $\mathrm{Cu}, \mathrm{Fe}$, and $\mathrm{Zn}$ in $\mathrm{HDC} / \mathrm{SMC}$

The $\mathrm{C} / \mathrm{N}$ of HDC/SMC were approximately 44.0 and $9.0 \mathrm{mg} \mathrm{kg}^{-1}$, respectively. The $\mathrm{pH}$ of HDC/SMC was 7.4 and 7.1, respectively. The total amounts of $\mathrm{Cu}, \mathrm{Fe}$, and $\mathrm{Zn}$ in used HDC were $10.4,910$, and $108 \mathrm{mg} \mathrm{kg}^{-1}$, respectively. The total amounts of $\mathrm{Cu}, \mathrm{Fe}$, and $\mathrm{Zn}$ in used SMC were $183,5,080$, and $670 \mathrm{mg} \mathrm{kg}^{-1}$, respectively. Figures 4 and 5 show the chemical forms of $\mathrm{Cu}, \mathrm{Fe}$, and $\mathrm{Zn}$ in HDC/SMC, respectively. $\mathrm{Cu}$ was primarily found in the organic complex fraction of HDC/SMC. Fe was primarily found in the residual fraction of HDC. Fe was primarily found in the organic complex and residual fractions of SMC. Zn was primarily found in the iron and manganese oxide fractions of HDC/SMC.

Chemical forms of $\mathrm{Cu}, \mathrm{Fe}$, and $\mathrm{Zn}$ in silica gel

Figure 6 shows the chemical forms of $\mathrm{Cu}, \mathrm{Fe}$, and $\mathrm{Zn}$ in silica gel. Slight amount of $\mathrm{Cu}$ was detected, and its chemical form did not show a specific pattern. The total concentration of Fe in silica gel was approximately $20 \mathrm{mg}$ $\mathrm{kg}^{-1}$. Fe was primarily found in the iron and manganese
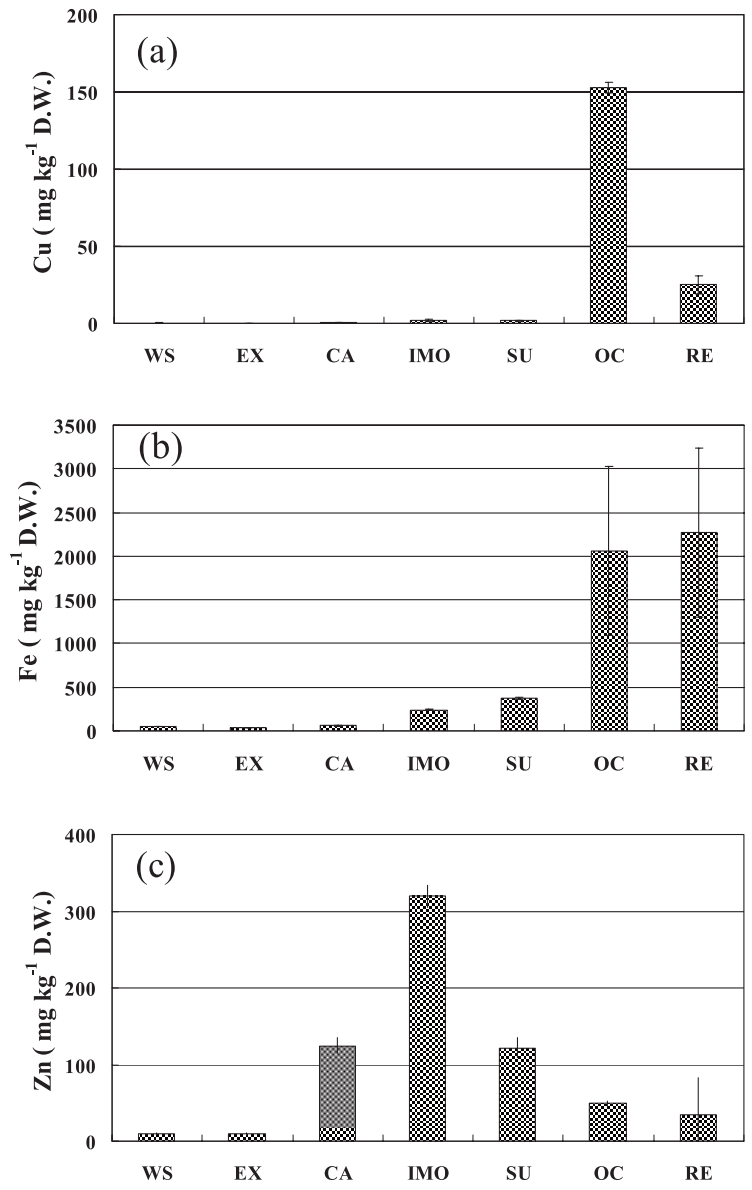

Fig. 5 Chemical forms of $\mathrm{Cu}(\mathrm{a}), \mathrm{Fe}(\mathrm{b})$, and $\mathrm{Zn}(\mathrm{c})$ in swine manure compost (SMC). WS: water soluble, EX: exchangeable, CA: carbonate, IMO: iron and manganese oxide, SU: sulfide, OC: organic complex, and RE: residual. Vertical bars indicate standard errors.
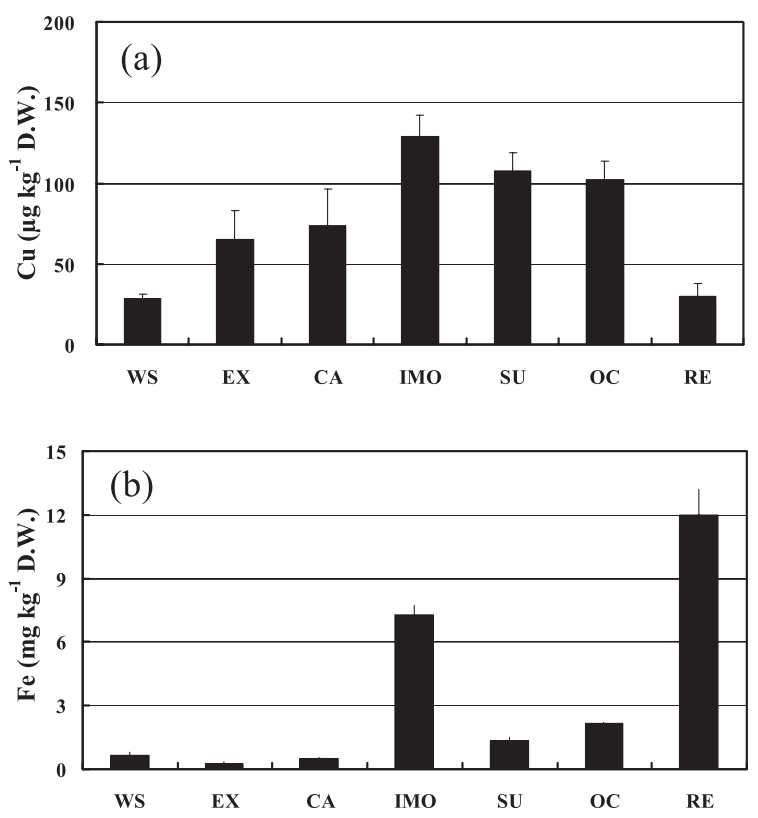

Fig. 6 Chemical forms of $\mathrm{Cu}$ (a) and $\mathrm{Fe}$ (b) in silica gel. WS: water soluble, EX: exchangeable, CA: carbonate, IMO: iron and manganese oxide, SU: sulfide, OC: organic complex, and RE: residual. Vertical bars indicate standard errors. 

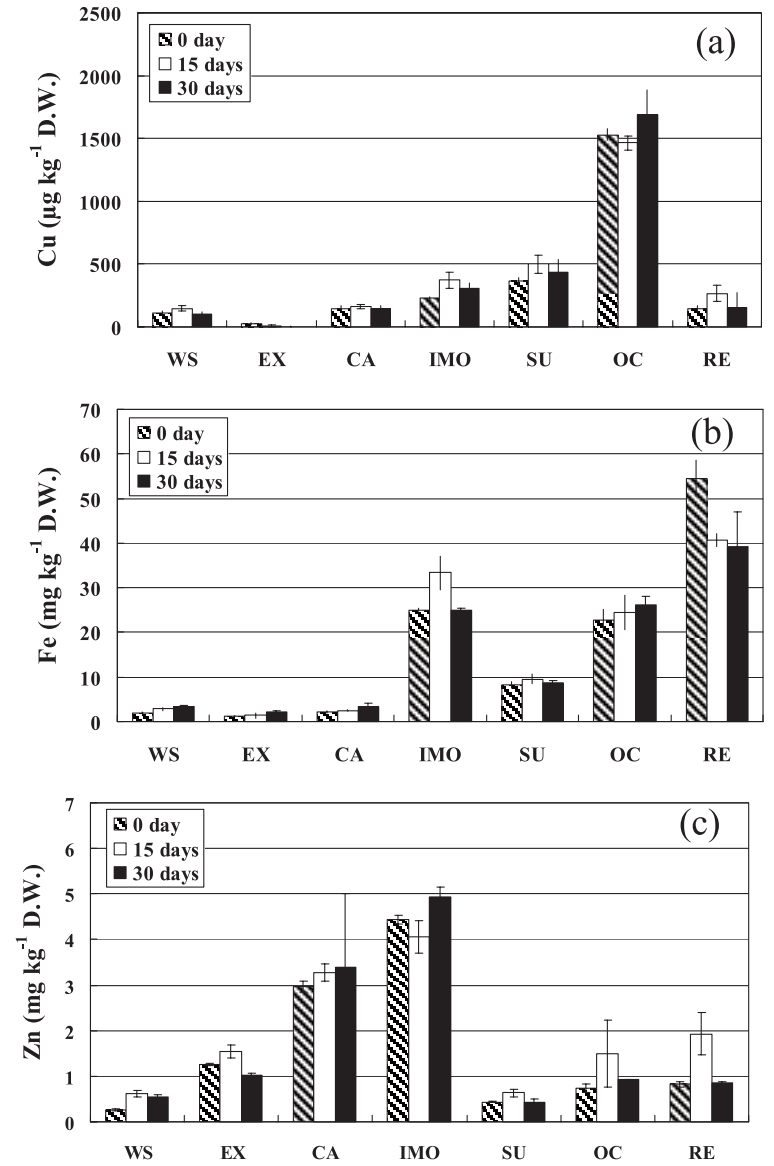

Fig. 7 Chemical forms of $\mathrm{Cu}(\mathrm{a}), \mathrm{Fe}(\mathrm{b})$, and $\mathrm{Zn}$ (c) in HDCsilica gel. WS: water soluble, EX: exchangeable, CA: carbonate, IMO: iron and manganese oxide, SU: sulfide, OC: organic complex, and RE: residual. Vertical bars indicate standard errors.

oxide and residual fractions. Zn was not detected in silica gel at all.

Chemical forms of $\mathrm{Cu}, \mathrm{Fe}$, and $\mathrm{Zn}$ in HDC/SMC-silica gel

Figure 7 shows the chemical forms of HDC-silica gel at 0,15 , and 30 days. $\mathrm{Cu}$ was found in the organic complex fraction. The concentration change for each temporal chemical form was not identified.

$\mathrm{Fe}$ was primarily found in the iron and manganese oxide, organic complex, and residual fractions. The concentration change of the temporal chemical forms in watersoluble, exchangeable, carbonate, sulfide, and organic complex fractions were not identified. In the iron and manganese oxide fraction, the concentration of $\mathrm{Fe}$ increased during the 0 to 15 day period; however, it decreased after 30 days. The Fe concentration in the residual fraction decreased after 15 days. It is possible that the concentration of $\mathrm{Fe}$ in the residual fraction would continuously decrease. Except for the iron and manganese oxide and residual fraction, the concentration change for each temporal chemical form was not identified. $\mathrm{Zn}$ was primarily found in the carbonate and iron and manganese oxide fractions of HDCsilica gel. Although the concentration of $\mathrm{Zn}$ in the organic complex and residual fractions increased during the first 15 days, it decreased after 30 days. Therefore, except organic
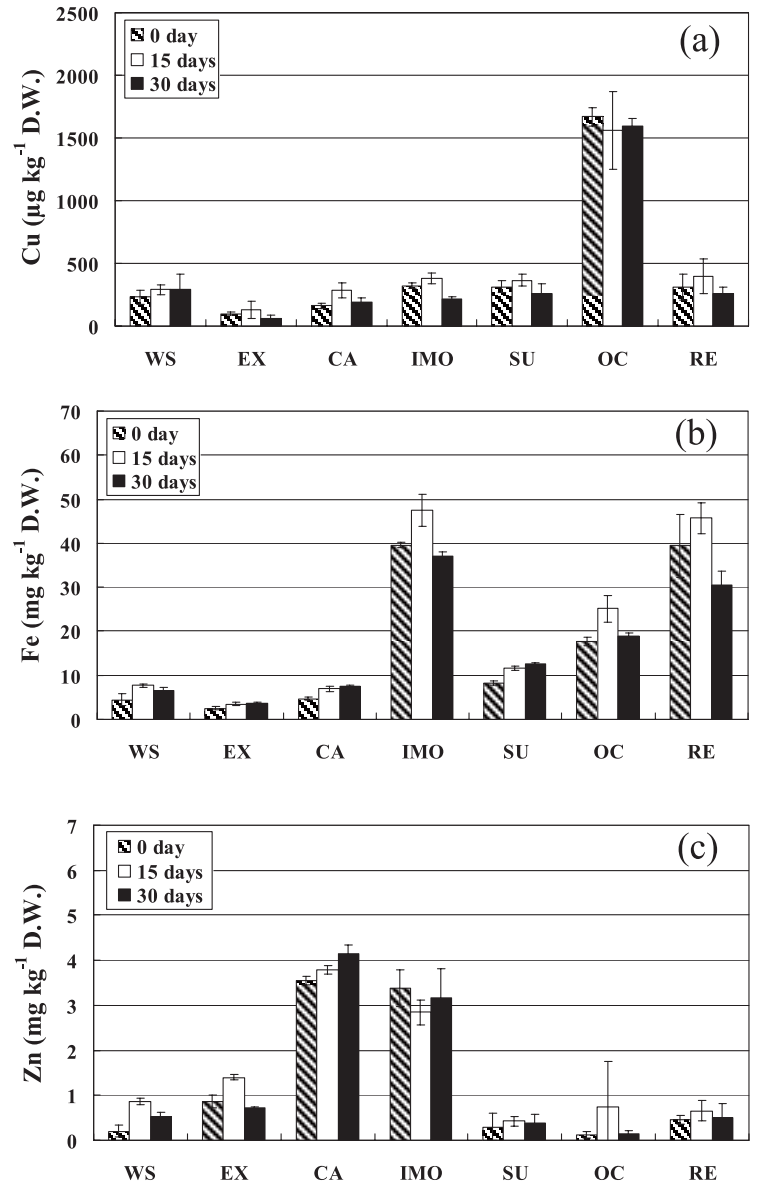

Fig. 8 Chemical forms of $\mathrm{Cu}(\mathrm{a}), \mathrm{Fe}(\mathrm{b})$, and $\mathrm{Zn}(\mathrm{c})$ in SMCsilica gel. WS: water soluble, EX: exchangeable, CA: carbonate, IMO: iron and manganese oxide, SU: sulfide, OC: organic complex, and RE: residual. Vertical bars indicate standard errors.

complex and residue fraction, the concentration change for each chemical form was not identified.

Figure 8 shows the chemical forms of $\mathrm{Cu}, \mathrm{Fe}$, and $\mathrm{Zn}$ in SMC-silica gel. Similar to $\mathrm{Cu}$ in HDC-silica gel, $\mathrm{Cu}$ in SMC-silica gel was primarily found in the organic complex fraction. The concentration change in each fraction was not observed. Similar to Fe in HDC-silica gel, Fe in SMCsilica gel was primarily found in the iron and manganese oxide, organic complex, and residual fractions. Concentration of the temporal chemical forms in watersoluble, exchangeable, carbonate, and sulfides fractions did not change. The concentration of $\mathrm{Fe}$ in the iron and manganese oxide, organic complex, and residual fractions increased during the 0 to 15 day period; however, it decreased after 30 days. $\mathrm{Zn}$ was primarily found in the carbonate and iron and manganese oxide fractions of SMCsilica gel. The concentration of $\mathrm{Zn}$ in the water-soluble and exchangeable fractions increased during the 0 to 15 day period and decreased after 30 days. Therefore, except watersoluble, exchange fraction, the concentration change for each temporal chemical form was not identified.

Change of chemical forms of $\mathrm{Cu}, \mathrm{Fe}$, and $\mathrm{Zn}$ in the HDC/SMC-silica gel medium in the cultivation experiment

Analysis of variance (ANOVA) and the Tukey- 

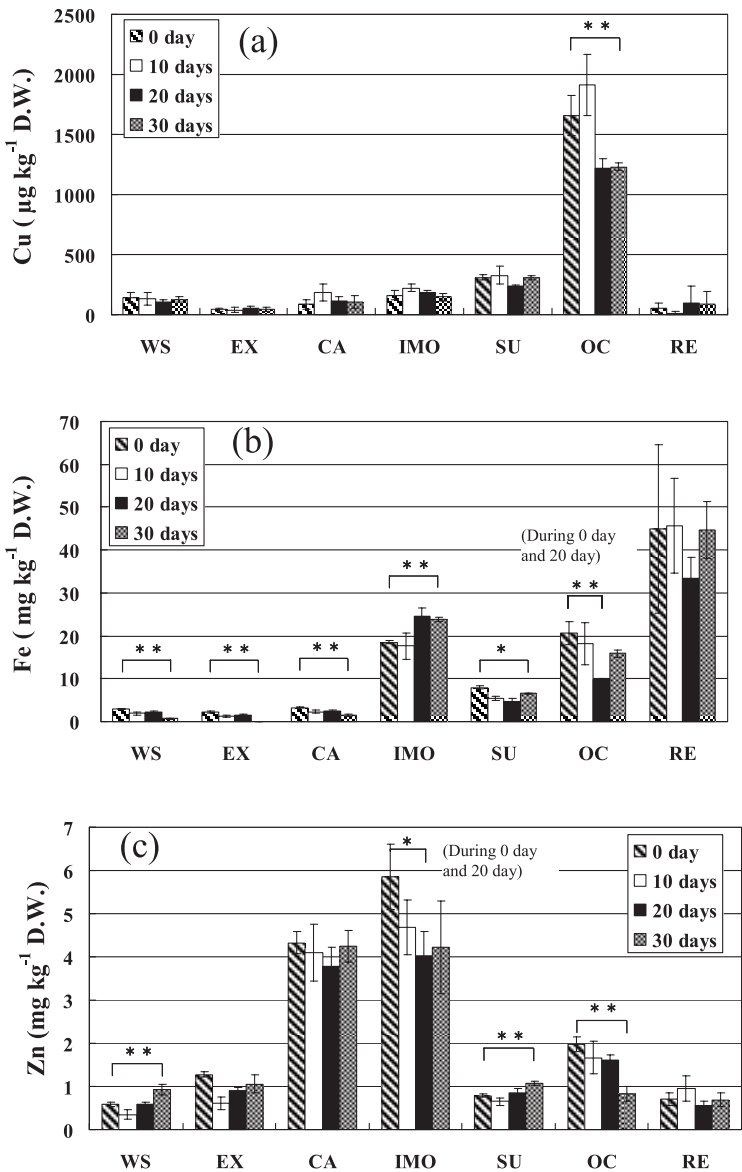

Fig. 9 Chemical forms of $\mathrm{Cu}$ (a), $\mathrm{Fe}$ (b), and $\mathrm{Zn}$ (c) in HDCsilica gel. All fractions were analyzed by ANOVA and the Tukey-Kramer test. The reference symbol (*) indicates a significant difference from day 0 to day 30 . WS: watersoluble, EX: exchangeable, CA: carbonates, IMO: iron and manganese oxides, SU: sulfides, OC: organic complex, and RE: residual. Vertical bars indicate standard errors. (*: $P<0.05, * *: P<0.01$ )

Kramer test were used to identify significant differences. Figure 9 shows the concentrations of each chemical form of $\mathrm{Cu}, \mathrm{Fe}$, and $\mathrm{Zn}$ in the HDC-silica gel medium during cultivation. Most $\mathrm{Cu}$ was found in the organic complex fraction. In the organic complex fraction, the concentration of $\mathrm{Cu}$ decreased significantly after 20 days and remained unchanged after 30 days. Fe in the HDC-silica gel medium was primarily found in the iron and manganese oxide, organic complex, and residual fractions. In the iron and manganese oxide fraction, the concentration of $\mathrm{Fe}$ increased significantly after 20 days and remained unchanged after 30 days. In the organic complex fraction, although the concentration of Fe decreased during the 10 to 20 day period, it increased during the 20 to 30 day period. There was no significant difference in the residual fraction. $\mathrm{Zn}$ in the HDC-silica gel medium was primarily found in the carbonate, iron and manganese oxide, and organic complex fractions. The concentration of $\mathrm{Zn}$ at day 30 was higher than that at day 0 in the water-soluble fraction. No significant difference was observed in the carbonate fraction. In the iron and manganese oxide fraction, the concentration of $\mathrm{Zn}$ at day 20 was significantly lower than that at day 0 . The
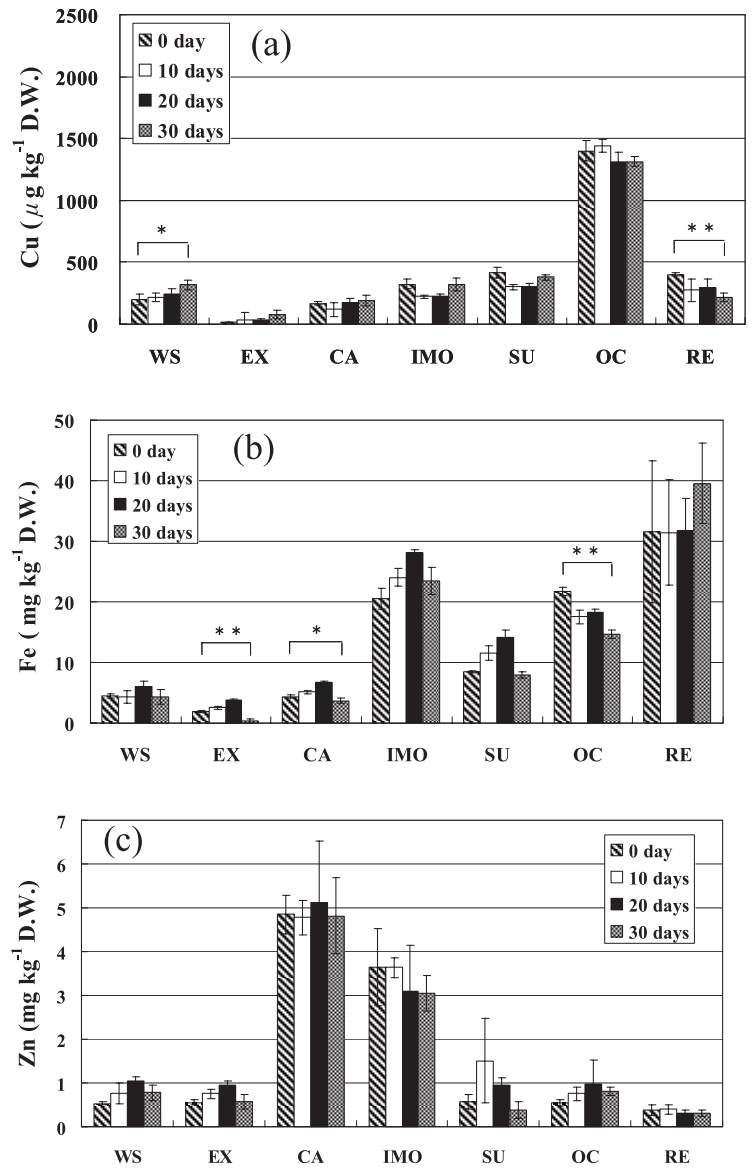

Fig. 10 Chemical forms of $\mathrm{Cu}$ (a), $\mathrm{Fe}(\mathrm{b})$, and $\mathrm{Zn}$ (c) in SMCsilica gel. All fractions were analyzed by ANOVA and the Tukey-Kramer test. The reference symbol (*) indicates a significant difference from day 0 to day 30. WS: watersoluble, EX: exchangeable, CA: carbonate, IMO: iron and manganese oxide, SU: sulfide, OC: organic complex, and RE: residual. Vertical bars indicate standard errors. (*: $P$ $<0.05$, **: $P<0.01)$

concentration of $\mathrm{Zn}$ in the organic complex fraction decreased gradually but significantly during the 0 to 30 day period. In addition, there was a significant difference between the concentration of $\mathrm{Zn}$ at day 0 and that after 30 days.

Figure 10 shows the concentrations of $\mathrm{Cu}, \mathrm{Fe}$, and $\mathrm{Zn}$ for each fraction in the SMC-silica gel medium after cultivation. $\mathrm{Cu}$ was primarily found in the organic complex fraction. The concentration of $\mathrm{Cu}$ at day 30 was higher than at day 0 in the water-soluble fraction. In the residual fraction, the concentration of $\mathrm{Cu}$ at day 30 was lower than that at day 0 . No significant difference was observed in the organic complex fraction. Fe in the SMC-silica gel media was primarily found in the iron and manganese oxide, organic complex, and residual fractions. Although the concentrations of $\mathrm{Fe}$ in the iron and manganese oxide and sulfide fractions increased during the 0 to 20 day period, it decreased after 30 days. In the organic complex fraction, the concentration of Fe gradually decreased, and there was a significant difference between the concentration of $\mathrm{Fe}$ at day 0 and that after 30 days. There was no significant difference in the concentration of $\mathrm{Fe}$ in the residual fraction. $\mathrm{Zn}$ was primarily found in the carbonate and iron and 


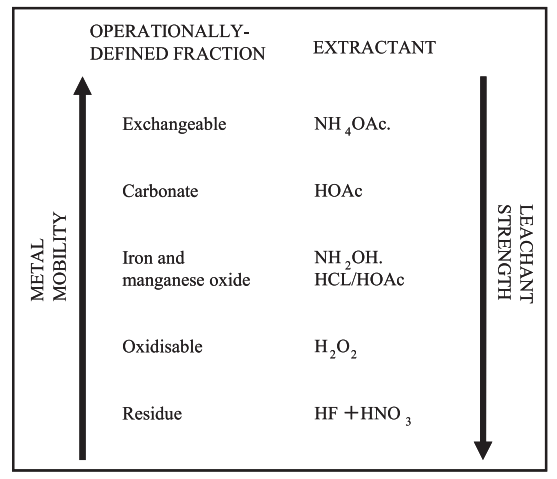

Fig. 11 Relationship between metal mobility in the different operationally-defined phases and leachant strength of common chemical reagents used for the sequential extraction.

manganese oxide fractions, and there was no significant difference between the concentration of $\mathrm{Zn}$ at day 0 and that after 30 days in any fraction.

\section{DISCUSSION}

Concentrations and chemical forms of $\mathrm{Cu}, \mathrm{Fe}$, and $\mathrm{Zn}$ in $\mathrm{HDC} / \mathrm{SMC}$

The concentration of $\mathrm{Cu}, \mathrm{Fe}$, and $\mathrm{Zn}$ in $\mathrm{SMC}$ was higher than that in HDC. This was thought to be due to heavy metals added to pig feed as a nutrient supplement. Orihara et al. (2002) investigated 32 types of SMC and estimated the average concentration of $\mathrm{Cu}$ and $\mathrm{Zn}$ to be 184 $\mathrm{mg} \mathrm{kg}{ }^{-1}$ and $630 \mathrm{mg} \mathrm{kg}^{-1}$, respectively, which are average levels of $\mathrm{Cu}$ and $\mathrm{Zn}$ in SMC in Japan. Zubillaga and Lavado (2006) reported that the $\mathrm{Cu}$ and $\mathrm{Zn}$ concentrations in horse manure were $11.8 \mathrm{mg} \mathrm{kg}^{-1}$ and $62.5 \mathrm{mg} \mathrm{kg}^{-1}$, respectively. It was surmised that $\mathrm{Cu}$ tends to strongly bind to organic matter in HDC/SMC. Some researchers have reported that $\mathrm{Cu}$ was primarily found in organic complex fraction in swine manure and sludge (Miller et al., 1986; Hsu and Lo, 2001; Su and Wong, 2003). It was also thought that $\mathrm{Fe}$ had combined with organic matter or was taken into the structure of minerals in HDC/SMC. The stability of divalent cation chelates follows the IrvingWilliams series $\left(\mathrm{Mn}^{2+}<\mathrm{Fe}^{2+}<\mathrm{Co}^{2+}<\mathrm{Ni}^{2+}<\mathrm{Cu}^{2+}>\mathrm{Zn}^{2+}\right)$ (Vlek, 1985). Since the tendency of $\mathrm{Zn}$ to combine with organic matter is weaker than that of $\mathrm{Cu}$, it is supposed that the distribution rate of $\mathrm{Zn}$ contained in the organic complex fraction will be less than that of $\mathrm{Cu}$.

Transformation of $\mathrm{Cu}, \mathrm{Fe}$, and $\mathrm{Zn}$ chemical forms in HDC/SMC-silica gel

Following the acclimatization experiment, a difference was observed between the distribution patterns of the chemical forms of $\mathrm{Fe}$ and $\mathrm{Zn}$ in HDC/SMC and those of Fe and $\mathrm{Zn}$ in HDC/SMC-silica gel (Figs. 4, 5, 7, and 8). For example, although $\mathrm{Fe}$ mainly was found in the residual fraction in HDC, besides residual fraction, Fe mainly found in iron and manganese oxide and organic complexes fractions in HDC-silicagel. On the other hand, although $\mathrm{Zn}$ mainly found in the iron and manganese oxide fraction in $\mathrm{SMC}$, besides iron and manganese oxide fraction, $\mathrm{Zn}$ mainly found in carbonate fraction in SMC-silicagel.
Filgueiras et al. (2002) reported that mobility of metal for every chemical form follows the order of Fig. 11. Therefore it is assumed that addition of silicagel to HDC/SMC made chemical form of Fe and $\mathrm{Zn}$ more mobile form. The some causes for this change were considered. First, the chemical forms of $\mathrm{Fe}$ and $\mathrm{Zn}$ in silica gel are more mobile than those of $\mathrm{Fe}$ and $\mathrm{Zn}$ in HDC/SMC-silica gel. Second, the addition of pure water to HDC/SMC-silica gel affects the chemical forms of Fe and $\mathrm{Zn}$. Fe remaining in washed silica gel was primarily found in the iron and manganese oxide and residual fractions (Fig. 6). However, the amount of $\mathrm{Fe}$ in silica gel was negligible compared to the total amount of Fe in HDC/SMC-silica gel. Silica gel did not contain $\mathrm{Zn}$; therefore, it did not affect $\mathrm{Fe}$ and $\mathrm{Zn}$ concentrations in each fraction.

It has been reported that humidified compost generates $\mathrm{CO}_{2}$ by the activity of micro-organisms (Nakasaki et al., 1985; Paillat et al., 2005; Matsuda et al., 2006). In this experiment, generated $\mathrm{CO}_{2}$ would react with $\mathrm{Fe}$ and $\mathrm{Zn}$ combined with organic matter and other minerals. Consequently, it is possible that $\mathrm{Fe}$ and $\mathrm{Zn}$ changed to a carbonate. The generalized form of the reaction is shown in Eq. 1.

$$
\begin{gathered}
(\mathrm{SO})_{2} \mathrm{M}+\mathrm{H}_{2} \mathrm{O}+\mathrm{CO}_{2}=2 \mathrm{SOH}+\mathrm{MCO}_{3} \\
\mathrm{SO}: \mathrm{Si}^{-} \mathrm{O}^{-}, \mathrm{AI}^{-} \mathrm{O}^{-}, \mathrm{COO} \text {, etc. } \\
\mathrm{M}^{2+}: \mathrm{Cu}^{2+}, \mathrm{Fe}^{2+}, \mathrm{Zn}^{2+}, \text { etc. }
\end{gathered}
$$

It was assumed that the carbonate form of $\mathrm{Fe}$ and $\mathrm{Zn}$ was likely to change to an exchangeable and water-soluble form because of the abundance of hydroxyl groups on the surface of the silica gel. In addition, it was assumed that protons would be ionized from hydroxyl groups on the surface of silica gel and interacts with chemical forms of $\mathrm{Fe}$ and $\mathrm{Zn}$ in HDC/SMC. However in this research, the mechanism was not revealed.

Bioavailable chemical forms and storage (sink) of $\mathrm{Cu}$, $\mathrm{Fe}$, and $\mathrm{Zn}$ in the HDC/SMC-silica gel medium

Since the concentration of $\mathrm{Cu}$ in the organic complex fraction significantly decreased during the 0 to 30 day period and the concentrations of $\mathrm{Cu}$ in the water-soluble and exchangeable fractions remained unchanged (Fig. 9-a), $\mathrm{Cu}$ in the organic complex fraction was most likely watersoluble and would be available for plants. Therefore, it was considered that the organic complex fraction stored $\mathrm{Cu}$. In some reports, this fraction has been referred to as a "sink" (Filgueiras et al., 2002; Zhao et al., 2011), and in other reports it has been referred to as a "pool" (Novak et al., 2004). Mclaren and Crawford (1973) reported that the concentration of $\mathrm{Cu}$ in a soil solution was controlled by equilibrium processes involving specifically adsorbed $\mathrm{Cu}$ and that the bulk of the available soil $\mathrm{Cu}$ reserves resided in the organic bond fraction. Since the concentration of Fe in the iron and manganese oxide fraction of the HDC-silica gel medium increased and that in the organic complex fraction of the HDC-silica gel medium decreased (Fig. 9-b), it was possible that protons ionized from silica gel were exchanged for $\mathrm{Fe}$ combined with organic matter. Consequently, Fe would transfer to other more watersoluble fractions. Therefore, the organic complex fraction 
was considered to store $\mathrm{Fe}$, which has been proposed by some researchers. As for $\mathrm{Zn}$, little change was observed in $\mathrm{Zn}$ fraction as the chemical form that would be potentially bioavailable such as water-soluble, exchangeable and carbonate. However, the concentration of non-bioavailable $\mathrm{Zn}$ in the iron and manganese oxide, and organic complex fractions decreased during the cultivation experiment (Fig. 9c). It was considered that, similar to $\mathrm{Cu}$ and $\mathrm{Fe}$, the iron and manganese oxide, and organic complex fractions also store $\mathrm{Zn}$ in the HDC-silica gel medium. The iron and manganese oxide (Filgueiras et al., 2002), carbonate, sulfide, and organic complex fractions (Basta et al., 2005) were proposed as important sinks for trace elements in the soil or soil-residual system.

In contrast, $\mathrm{Cu}$ was probably not stored in the SMCsilica gel medium because the concentration of $\mathrm{Cu}$ did not decrease significantly in the organic complex fraction (Fig. 10-a). In the SMC-silica gel medium, the concentration of $\mathrm{Fe}$ in the organic complex fraction decreased significantly (Fig. 10-b). Therefore, it is supposed that only Fe was stored in the organic complex fraction. Zn was probably not stored in the SMC-silica gel medium because no significant decrease in concentration was evident in any fraction (Fig. $10-c)$.

We propose that the storage of $\mathrm{Cu}$ and $\mathrm{Fe}$ occurs in the organic complex fraction and the storage of $\mathrm{Zn}$ occurs in the iron and manganese oxide and organic complex fractions.

The authors would like to thank Professor Jay Melton for his review of this paper.

\section{REFERENCES}

Bartoli, F., Philippy, R. 1987. The colloidal stability of variable-charge mineral suspensions. Clay Miner. 22: 93-107.

Basta, N. T., Ryan, J. A., Chaney, R. L. 2005. Trace element chemistry in residual-treatmant soil: Key concepts and metal bioavailability. J. Environ. Qual. 34: 49-63.

Bohn, H. L., Myer, R. A., O'Connor, G. A. 2001. Soil Chemistry, Wiley, New York, pp 144

European Commission. 2003. Opinion of the scientific committee for animal nutrition on the use of copper in feeding stuffs. http://ec.europa.eu/food/fs/sc/scan/out126_bis_en.pdf

Filgueiras, A. V., Lavilla, I., Bendicho, C. 2002. Chemical sequential extraction for metal partitioning in environmental solid samples. J. Environ. Monit. 4: 823-857.

Gromwell, G. L., Monegue, H. J., Stahly, T. S. 1993. Long-term effects of feeding a high copper diet to sows during gestation and lactation. J. Anim. Sci. 71: 2996-3002.

Hseu, Z.-Y. 2004. Evaluating heavy metal contents in nine composts using four digestion methods. Bioresour. Technol. 95: 53-59.

Hsu, J.-H., Lo, S.-L. 2001. Effect of composting on characterization and leaching of copper, manganese, and zinc from swine manure. Environ. Pollut. 114: 119-127.

Ikefuchi, M. 2007. Annual report on food, agriculture and rural areas in Japan fy, Ministry of Agriculture, Forestry and Fisheries, pp 21. http://www.maff.go.jp/e/annual_report/2007/pdf/e_all.pdf

Japan Livestock Industry Association. 2005. Japansese feeding standard for swine (in Japanese), pp 70

Jolliff, J. S., Mahan, D. C. 2011. Effect of injected and dietary iron in young pigs on blood hematology and post-natal pig growth performance. J. Anim. Sci. 89: 4068-4080.

Kitano, Y., Fujiyoshi, R. 1980. Selective chemical leaching of cadmium, copper manganese and iron in marine sediments. Geochem. J. 14: 113-122.

Matsuda, A., Watanabe, R., Ochiai, K., Matoh, T. 2006. Quality evaluation of organic amendments based on their $\mathrm{CO}_{2}$ evaluation rates sold at local markets around Kyoto city. (in Japanese with English summary) Jpn. J. Soil Sci. Plant Nutr. 77: 387-393.

Mcbride, M. B. 1994. Environmental chemistry of soils. Oxford Univ, New York, pp 122-127.

Mclaren, R. G., Crawford, D. V. 1973. Studies on soil copper I. The fractionation of copper in soils. J. Soil Sci. 24: 172-181.

Miller, W. P., Martens, D. C., Zelazny, L. W., Kornegay, E. T. 1986. Forms of solid phase copper in copper-enriched swine manure. J. Environ. Qual. 15: 69-72.

Ministry of Agriculture, Forestry, and Fisheries. 1999. Act on the appropriate treatment and promotion of utilization of livestock manure.

http://law.e-gov.go.jp/htmldata/H11/H11HO112.html.

Ministry of Agriculture, Forestry and Fisheries. 2005. Guideline for agriculture, pp 137

http://www.maff.go.jp/j/seisan/kankyo/hozen_type/ h_sehi_kizyun/pdf/ntuti23.pdf

Ministry of Agriculture, Forestry and Fisheries. 2007. Current situation and problem of farmland, pp 11-12. http://www.maff.go.jp/j/study/kankyo_hozen/01/pdf/data03.pdf

Mizukami, S., Abe, S., Ieiri, S. 2006. Opitimum levels of copper and zinc in weaning pigs under different sanitary conditions. (in Japanese with English summary) Jpn. J. Swine Sci. 43: $174-179$.

Nakasaki, K., Sasaki, K., Sasaki, M., Shoda, M., Kubota, H. 1985. Change in microbial numbers during thermophilic composting of sewage sludge with reference to $\mathrm{CO}_{2}$ evolution rate. Appl. Environ. Microbiol. 49: 37-41.

Nakashima, S. 1982. Partitioning of heavy metals (Mn, Fe, As, $\mathrm{Cd}, \mathrm{Pb}, \mathrm{Cu}, \mathrm{Zn}, \mathrm{Co}$ and $\mathrm{Ni}$ ) into selective chemical fractions in sediment cores from lake Biwa. (in Japanese with English summary) Jpn. J. Limnol. 43: 67-80.

Novak, J. M., Watts, D. W., Stone, K. C. 2004. Copper and Zinc accumulation, profile distribution, and crop removal in coastal plain soils receiving long-term, intensive applications of swine manure, Trans. ASAE. 47: 1513-1522.

Orihara, K., Kamiyama, K., Fujiwara, S. 2002. Characteristics of the heavy metal content in animal manure compost. (in Japanese with English summary) Jpn. J. Soil Sci. Plant Nutr. 73: 403-409.

Paillat, J.-M., Robin, P., Hassouna, M., Leterme, P. 2005. Predicting ammonia and carbon dioxide emissions from carbon and nitrogen biodegradability during animal waste composting. Atmos. Environ. 39: 6833-6842.

Saeki, K. 2006. Adsorption sequence of heavy metal divalent ions on silica. (in Japanese with English summary) J. Clay Sci. Soc. Jpn. 45: 90-94.

Su, D. C., Wong, T. W. C. 2003. Chemical speciation and phytoavailability of $\mathrm{Zn}, \mathrm{Cu}, \mathrm{Ni}$ and $\mathrm{Cd}$ in soil amended with fly ash-stabilized sewage sludge. Environ Int. 29: 895-900.

Tessier, A., Campbell, P. G. C., Bisson, M. 1979. Sequential extraction procedure for the speciation of particulate trace metals. Anal. Chem. 51: 844-851.

Vlek, P. L. G. 1985. Micronutrients in Tropical Food Crop Production, Springer, pp 26

Zhao, K., Liu, X., Zhang, W., Xu, J., Wang, F. 2011. Spatial dependence and bioavailability of metal fractions in paddy fields on metal concentrations in rice grain at a regional scale. J. Soils Sediments 11: 1165-1177.

Zubillaga, M. S., Lavado, R. S. 2006. Phytotoxicity of biosolids compost at different degrees of maturity compared to biosolids and animal matures. Compost. Sci. Util. 14: 267270 . 